\title{
Experimental Study of Mechanical Properties and Drilling Properties of Glass Fibre Composite
}

\author{
R.Balaji*, C.Sivakandhan**, P.Munusamy***, D.muthukumar**** \\ *(Assistant Professor, Department of Mechanical Engineering, Er.Perumal Manimekalai College of \\ Engineering-Hosur-635117) \\ **(Professor, Department of Mechanical Engineering, Er.Perumal Manimekalai College of Engineering- \\ Hosur-635117) \\ ***(Assistant Professor, Department of Mechanical Engineering, Er.Perumal Manimekalai College of \\ Engineering-Hosur-635117) \\ ****(Assistant Professor, Department of Mechanical Engineering, Er.Perumal Manimekalai College of \\ Engineering-Hosur-635117)
}

\begin{abstract}
The use of glass fiber polymer composite materials are on the rise due to their special properties like high specific strength and stiffness, excellent corrosion resistant, high damping, low thermal expansion high factor toughness. Majorly it is used in the fields of aerospace and automobiles especially in defense use. Though, manufacturing of these of these laminates are easy to their required shapes but obtaining a drilling in the laminate poses difficulty, due to its anisotropic non homogeneous nature. The rate of rejection at the final stage due to non selection of right machining drill parameters which makes the researchers to find the optimal solution effectively. Sometimes rejection rate accounts up-to $60 \%$ and hole drilling being one of the last operations creates many problems, mainly delamination stress concentration and improper hole quality with impounding higher cost factor. This paper presents an investigation on aspects of various mechanical properties and drilling of Glass fibre Mat Composite. Drilling experiments was conducted to study the delamination factor and hole quality on GFRP composites. Also the study carried out for Tensile Strength, Hardness and Fle xural Strength of Glass Fibre Composite.
\end{abstract}

Keywords: glass fiber poly mer, fiber Mat

\section{INTRODUCTION}

The use of composites has been increased in engineering sector which has been diversifying in various fields as defense structural construction air craft construction .composite materials is a combination of two different or dissimilar materials to obtain the good material properties generally engineering composites are formed by individual piles to form continuous fiber straight fibers are fibers that are embedded which are laminated layer by layer to obtain a required net structure

The main use of composite in various engineering fields to its excellent specific strength and stiffness, light weight structures, and also ease of complex shapes manufacturing with their good corrosion and fatigue resistance

Two constituents in composites one is matrix and the other one is reinforcement .matrix which has continuous constituents and has greater in quantity, whereas reinforcement is to enhance the mechanical properties which is based on the structure and its dimension the main function of matrix is to bind the fiber and also to distribute the load evenly between the fiber and protect them from damages mechanically and environ mentally
Generally composite can be classified in to two categories such as natural and made composites .man made composites are, under controlled condition and definite ratio binding two or more different materials the present work is done with fiber reinforced polymer which offers a wide range of advantages like light weight and high strength to weight ratio and also to ease to fabricate the part than others.

Dilli Babu[1], in his paper he investigated the drilling of Uni-Directional Hand Layup GFRP Laminates.This study with the objective of evaluating the cutting parameters (cutting velocity and feed rate) and the influence of the fibers under delamination factor $(\mathrm{Fd})$. The objective was to establish a correlation between cutting velocity and feed rate with the delamination of different fiberreinforced laminates. Concluded as the Hemp Fiber Reinforced Composites promote less damage than other fiber-reinforced composites, i.e., the delamination factor $(\mathrm{Fd})$ is smaller. The feed rate and cutting speed are seen to contribute the most to the delamination effect. 
D.Abdul budan[2], done a study of influence of fibre volume reinforcement In drilling gfrp laminates, on that the study Drilling experiments were conducted for tool wear, surface fin ish, dela mination factor and hole quality on GFRP composites. Fibre percentage in composite plays a vital role on drill ability of GFRP. Drilling of $70 \%$ fibre percentage content composites produced hazardous surface roughness. Better surface finish was obtained for the composite with $30 \%$ fibre volume content composites. Increase in fibre percentage has increased the surface roughness of the composites. As the drill bit proceeds during drilling, extensive pull out of fibres occurs which increases with the increase in the fibre volume fraction. Each individual pulled out fibres tends to form fibrils during drilling. Increase in fibre percentage lead to decrease of hole quality. The increase in the fibre percentage increased the probability of pulling out of fibres during drilling. It can also be explained on the fact that low coefficient of thermal conduction and accumulated heat stagnated around tool edge, causes excessive material flow behind tool edge. When the fiber content is low, at tool tip heat accumulates and large increase of temperature in work piece promotes plasticity by extensive chain sliding. Hence long chips were obtained. Whereas in higher fibre content composites, extensive plasticity was absent consequently brittle ceramic fibres were fractured easily. Hence small segment type chips were obtained. The fibre pull out and fibrils present near the hole exit forms the remainder of the laminate. Thus forms increased damage zone near the hole exit. Hence high delamination factor was obtained for the higher fibre concentration.

K.V.Arun [3], investigated the Drilling of Tio 2 and $\mathrm{ZnS}$ filled GFRP Composites. The volume fractions in the matrix were chosen as $1 \%, 2 \%$ and $3 \%$. Drilling has been conducted on a radial drilling machine. Speed of drilling and drill tool diameter were considered as the varying parameters with three levels. Hand lay-up technique of laminating the composites has been employed for composite fabrication. Two material compositions of Glass/Epo xy (G-E) composites were chosen namely G-TiO2-E and G-ZnS-E. Each material composition has been fabricated for three different volume fractions. He concluded as the thrust force generated during drilling of filled composites mainly depends upon drill diameter and the speed of drilling in the present case. Effect of filler volume on the Thrust generated is neglizable. Thrust force developed during drilling of $\mathrm{TiO} 2$ filled composites is more in comparison with $\mathrm{ZnS}$ filled Composites.

M.Sakthive1[4], in the paper Review on thrust force and torque in drilling of glass fiber reinforced polymer composite, made an attempt to review the work of some researchers who had conducted the experimental studies on drilling of polymer matrix composite material, namely drilling on glass fibre reinforced plastics. Delamination of GFRP composite material is mainly determined by feed rate and drill tool diameter. All these parameters have major contribution over the quality of the hole, the cutting speed is inversely proportional to the thrust force and torque.

B.V.Kavad [5], studied Effects of Drilling on Glass Fiber Reinforced Plastic. He attempts to review the influence of machining parameter on the delamination damage of GFRP during drilling. In conventional machining feed rate, tool material and cutting speed are the most influential factor on the delamination hence machining at higher speed, harder tool material and lower feed rate have lesser delamination of the GFRP. Concluded as the use of High Speed Machining is suitable for drilling GFRP ensuring low damage levels and it is an outstanding technology capable of improving productivity and lowering production costs. Vibration as sisted drilling and Ultrasonic assisted drilling have lesser thrust hence lesser delamination compared to conventional drilling, which indicate that both vibration assisted drilling and Ultrasonic assisted drilling are more appropriate for drilling of GFRP.

Rout et al[6]. Investigated the mechanical properties and erosion wear of glass fibre reinforced epoxy composite with filled and unfilled rice husk particulates. Experimental design was also done using Taguchi optimization technique to determine the optimal parameters, which minimizes the wear rate. They concluded that factors like filler content, impact velocity, impingement angle and erodent size has more significant effect on wear rate, and at 15 wt $\%$ of rice husk shows maximum wear resistance. Tensile modulus, hardness and impact energy improves with addition of filler content. Decline in flexural and tensile properties of the composites were noticed. Al-Hasani studied the tensile strength and hardness of glass fibre reinforced epoxy composite at different volume fraction as layers. Three types of composite samples were prepared, woven roving, randomly oriented and sandwich which consists of (woven roving and Random oriented). It was found that sandwich composite exhibits higher value of tensile strength $254 \mathrm{~N} / \mathrm{mm} 2$ whereas, nine layered glass fibre woven roving composites exhibited higher hardness of 62.1 BHN.

Amit Kumar Tanwer [7] in his paper he investigated Mechanical properties of GFRP. Experimental design was done with E-Glass, CGlass and S-Galss fibre mats with Uni-Directional and Bi-Directional. Used Arald ite as Epo xy and HV953 as Hardener. Compression and Tensile tests were conducted on UTM. In all the testing of properties of material as compression and tension on 
samples of uni and bi-directional glass fiber reinforced epoxy resin based polymer composites, following points have been concluded. Unidirectional oriented glass fiber epoxy composites have large value of all the properties such as Ultimate force, yield force, Compressive strength, Tensile strength, elongation etc. in tensile as well as compression test. It means unidirectional oriented glass fiber composites strength than Bidirectional. The comparis on between results of both, the value of ultimate force in Compressive test is greater than the value of ultimate force in tensile test in case of unidirectional alignment \& bidirectional alignment. It means Compressive Strength is more in Glass fiber based epoxy composites.

K.Alagarraja [8], in his paper he studied mechanical testing such as Tensile, Flexural and Imapct on Sical-GFRP Composites. Concluded as sisal- GFRP specimen gives tensile strength is low. The Maximum tensile force (MTF) of the sisalGFRP composite is in the range of $24.080 \mathrm{KN}$. The result indicates for flexural test in the sisal-GFRP is high compare glass and sisal fiber separately. The maximu $\mathrm{m}$ load is withstanding $500 \mathrm{~N}$ with $116 \mathrm{sec}$. In the compression test the result indicates that very high strength $28.180 \mathrm{KN}$ and the respectively displacement is $2.3 \mathrm{~mm}$. The maximum impact strength is obtained for the sisal-GFRP fiber composite and has the value of 18 joules. The Rockwell hardness tests the strength obtains 96.67 HRB. The results indicated that the incorporation of sisal fiber with GFRP can improve the properties and used as an alternate material for glass fiber reinforced poly mer composites.

Prasanna Kumar Ilankeeran [9], studied Axial Tensile Testing of Single Fibres. In that study the axial tensile modulus, ultimate strength and failure strain of single fibres are determined for carbon and glass fibres. ASTM D3379-75 standard is followed and a number of fibers are tested for statistical analysis. The axial tensile moduli measured are $246.7 \mathrm{GPa}$ and $93.3 \mathrm{GPa}$, respectively and strength are $3031.6 \mathrm{MPa}$ and 2035.9 MPa, respectively for carbon and glass fibres. Further, the respective axial tensile failure strains are 0.0137 and 0.0224. The error in the measurement of axial modulus is below $8 \%$ while for axial tensile strength is below $1 \%$.

Irina M.M.W[10], in the Paper Evaluation of Mechanical Properties of Hybrid Fiber Reinforced Polymer Composites and Their Architecture investigates the mechanical properties of three different arrangements of hybrid composites made from glass fiber (plain-woven and stitched bi-axial $\pm 45^{\circ}$ ) and plain-woven carbon fiber. Vacuum assisted resin transfer moulding method was employed to fabricate the hybrid composite panels. Mechanical properties such as tensile strength, flexural strength and volume fraction of the hybrid composites were determined per ASTM standards. By comparing three orientation schemes of carbon and E-glass fibers, mechanical performance for [CWW]6 hybrid composites is better than that of the others hybrid combination in terms of tensile and flexural mechanical performance. Although the replacement a portion of carbon will increase the overall costing of FRP composite, however it is still worthy to supplanted the low cost of pure FRP composites. Hybrid composites with lighter weight and higher strength are one of the key to moderate the shortage of petrol fuel as well as reduce the environmental burden of automotive vehicles or aeros pace structural.

\section{MATERIAL SELECTION}

\subsection{Fibre material}

Glass fiber is one of the commonly used among composite materials and are available in various forms one type is woven fabric in this present work woven fabric mat of $650 \mathrm{gsm}$ is used as base material.

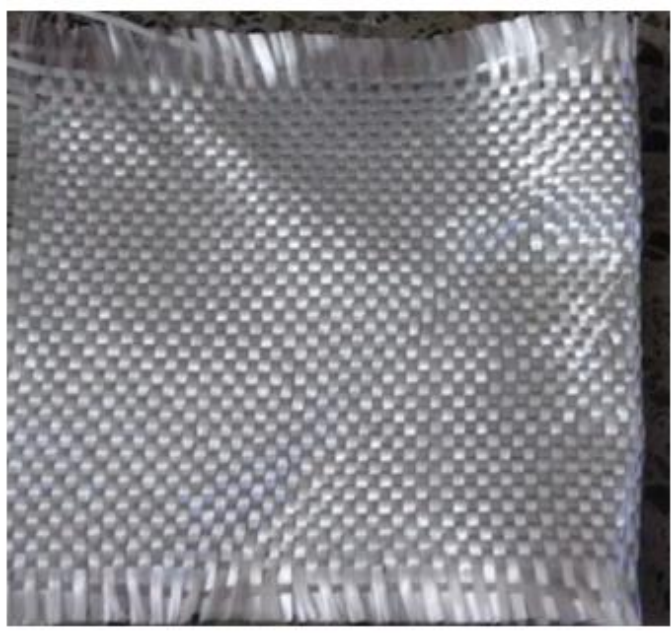

Woven Glass Fibre Mat

\subsection{Filler material}

Various types of particulate filler are used as reinforcement in polymer based composite. Among them Silicon Carbide (SiC), Alumina $\left(\mathrm{Al}_{2} \mathrm{O}_{3}\right)$, Zinc Oxide $(\mathrm{ZnO})$ and Titaniu $\mathrm{m}\left(\mathrm{TiO}_{2}\right)$ are most widely used as conventional filler. In the present work Silicon Carbide ( $\mathrm{SiC}$ ) and Zinc Oxide $(\mathrm{ZnO})$ are used as filler material. The properties of $\mathrm{SiC}$ and $\mathrm{ZnO}$ are like chemical inertness, and good hardness, strength and more over best suits where friction and wear condition are predominant and less expensive 

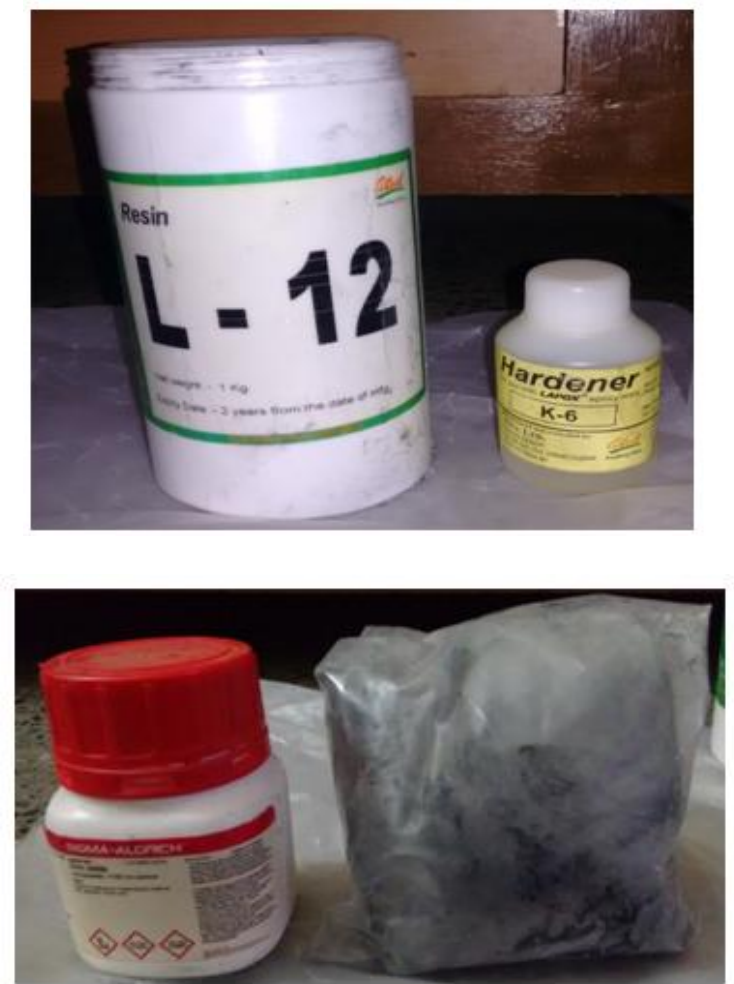

L-12 Epo xy and K-6 Hardener

Sic and $\mathrm{ZnO}$ Powders

\section{COMPOSITE FABRICATION}

In the present work Woven Glass Fibre Mat is taken as Base Material. The epoxy resin (L-12) and hardener (K-6) supplied by ATUL Ltd, Polymers Division were used as a matrix. Silicon Carbide ( $\mathrm{SiC})$ and Zinc Oxide ( $\mathrm{ZnO})$ is used as a filler material, having particle size in the range of $\mathrm{SiC}-80-100 \mu \mathrm{m}$ and $\mathrm{ZnO}-<100 \mathrm{~nm}$

Glass Fibre mat is placed on the Glass Plate and then mixture of resin, hardener, $\mathrm{SiC}$ and $\mathrm{ZnO}$ is coated on the Mat using Roller Brush. Then Another Fibre mat is placed above the previous one. Again Resin mixture is applied. This Procedure is repeated for next 9 Layers. On the top another Glass Plate is provided for holding the pressure. Then this arrangement is kept on room temperature for curing. After curing the Composite is taken and cutout to required shapes for testing and drilling

\subsection{Properties of $\mathrm{SiC}$}

Density- $3.2 \mathrm{~g} \mathrm{~m} / \mathrm{cm}^{3}$

Color-black

Fle xu ral strength-550mpa

Elastic modulus-410mpa

Posssion's ratio- 0.14

Compression strength-39000mpa

Hardnes s $-2800 \mathrm{~kg} / \mathrm{mm}^{2} \mathrm{~s}$

\subsection{Composition of Materials}

\begin{tabular}{|c|c|}
\hline Material & Weight \& Percentage \\
\hline Epoxy Resin & $2 \mathrm{~kg}$ \\
\hline Hardener & $0.2 \mathrm{~kg}$ \\
\hline $\mathrm{SiC}$ & $5 \%(0.1 \mathrm{~kg})$ \\
\hline $\mathrm{ZnO}$ & $2 \%(0.04 \mathrm{~kg})$ \\
\hline
\end{tabular}

\subsection{Curing of Composite}

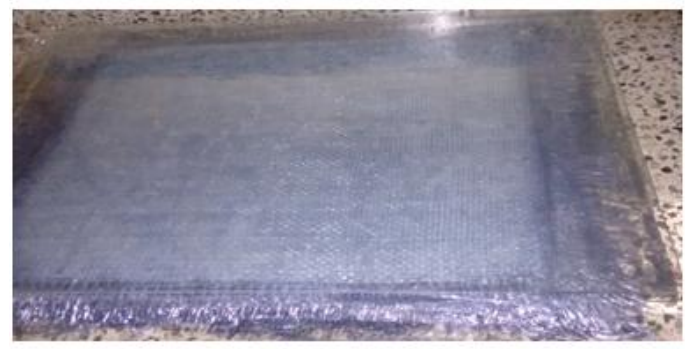

\subsection{Tensile Test}

\section{MECHANICAL TESTING AND DRILLING OF COMPOSITE}

The laminate is fabricated as per ASTM D638 standards in to the required dimension by suing wire cut and the edges are ground to finished surface and then the testing procedure involves placing the test specimen in the testing machine and applying tension to it until it fractures. The tensile force is recorded with the elongation of gauge section is recorded against the applied force.

Specimen Dimensions

Length $=290 \mathrm{~mm}$

Width $=24 \mathrm{~mm}$

Thickness $=5 \mathrm{~mm}$

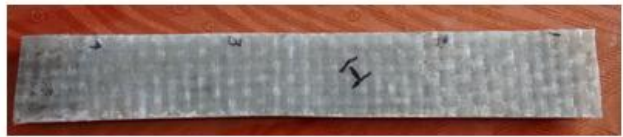

Tensile Test Specimen

\subsection{Flexural Test}

The flexural specimens are prepared as per the ASTM D790 standard. The 3-point fle xu re test is the most common flexural test for composite materials. Specimen deflection is measured by the crosshead position. Test results include flexural strength and displacement. The testing process involves placing the test specimen in the universal testing machine and applying force to it until it fractures and breaks.

\section{Specimen Dimensions}

Length $=185 \mathrm{~mm}$

Width $=26 \mathrm{~mm}$

Thickness $=4.8 \mathrm{~mm}$

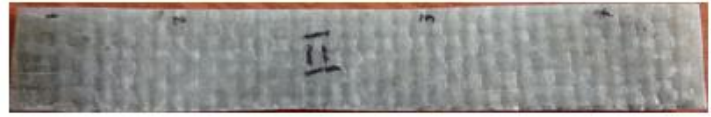

Fle xu ral Test Specimen 


\subsection{Hardness Test}

The Rockwell harness test carried out for the Composite material and obtained the result as applied $100 \mathrm{~kg}$ for $1 / 16$ inch penetrator the B scale reading is $46 \mathrm{HRB}$.

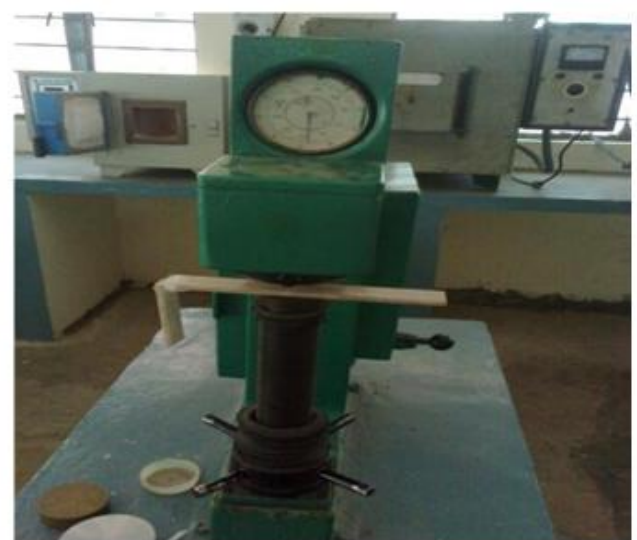

\subsection{Drilling Test}

Twist Drill Bit is used in this testing was $10 \mathrm{~mm}$ in dia. Drilling operations were done on CNC Milling Machine Supplied by ACEM icromatic, India.

\subsection{Delamination Mechanism}

From the various previous studies it is observed that the delamination occurs at the entry and exit side of the hole. Delamination by drill tool on either side follows different mechanis $\mathrm{m}$. The tool used acts as a power screw and due to the piercing effect of the drill tool over the surface of the laminate during drilling delamination occurs due to peeling effect of drill while drilling and is also known as peeling up mechanism similarly when the tool gets out of the laminate over the exit side the sub laminate under pressure gets delaminated as push out mechanism. In this study delamination factor for three speeds and feed rate were done.

\subsection{Design of Experiments}

Cutting Speed and Feed Rate are the Two most Important Parameters characterizing the Drilling Operation and Have been selected for Investigation.Table1 indicates the Factors to be studied and the assignment of the corresponding levels.

Levels of the variables used in the Drilling experiment

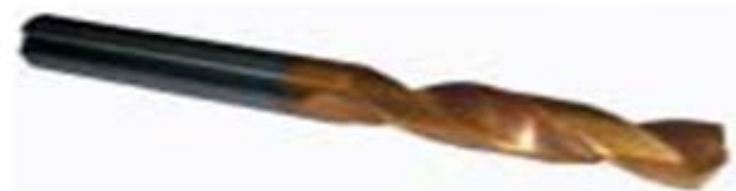

Drill Bit Used

\begin{tabular}{|c|c|c|c|}
\hline $\begin{array}{c}\text { Process } \\
\text { parameters }\end{array}$ & Minimum & Medium & Maximum \\
\hline $\begin{array}{c}\text { Cutting } \\
\text { speed (rpm) }\end{array}$ & 100 & 200 & 300 \\
\hline $\begin{array}{c}\text { Feed rate } \\
(\mathrm{mm} / \mathrm{rev})\end{array}$ & 0.10 & 0.20 & 0.30 \\
\hline
\end{tabular}

\subsection{Measure ment of Delamination Factor} $\left(\mathbf{F}_{\mathrm{d}}\right)$ :

The value of the dela mination factor $(\mathrm{Fd})$ can be calculated by using the following equation:

$$
\mathrm{F}_{\mathrm{d}}=\mathrm{Dmax} / \mathrm{D}
$$

Where,

$\mathrm{D}_{\max }$ - maximu $\mathrm{m}$ diameter of the damage around the hole periphery

D - Diameter of the drill

\section{RESULTS AND DISCUSSIONS}

\begin{tabular}{|c|c|c|c|}
\hline Test & $\bar{V}(\mathbf{r p m})$ & $\begin{array}{c}\mathbf{f} \\
(\mathrm{mm} / \mathrm{rev})\end{array}$ & $\begin{array}{l}\text { Delaminati on } \\
\text { Factor }\left(F_{d}\right)\end{array}$ \\
\hline 1 & \multirow{3}{*}{100} & 0.1 & 1.87 \\
\hline 2 & & 0.2 & 2.19 \\
\hline 3 & & 0.3 & 2.87 \\
\hline 4 & \multirow{3}{*}{200} & 0.1 & 1.6 \\
\hline 5 & & 0.2 & 1.97 \\
\hline 6 & & 0.3 & 2.14 \\
\hline 7 & \multirow{3}{*}{300} & 0.1 & 1.36 \\
\hline 8 & & 0.2 & 1.96 \\
\hline 9 & & 0.3 & 1.98 \\
\hline
\end{tabular}

\section{Graph}

\section{For s peed (V) 100 r pm}

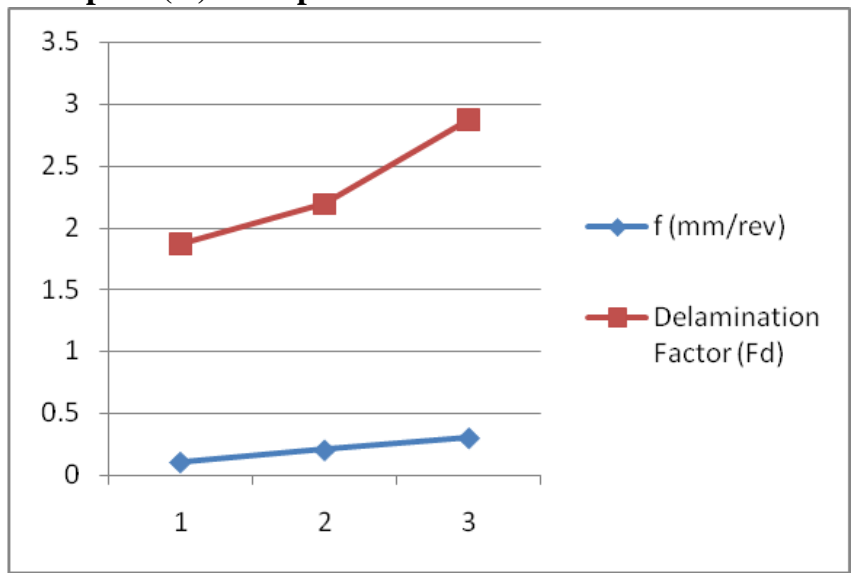




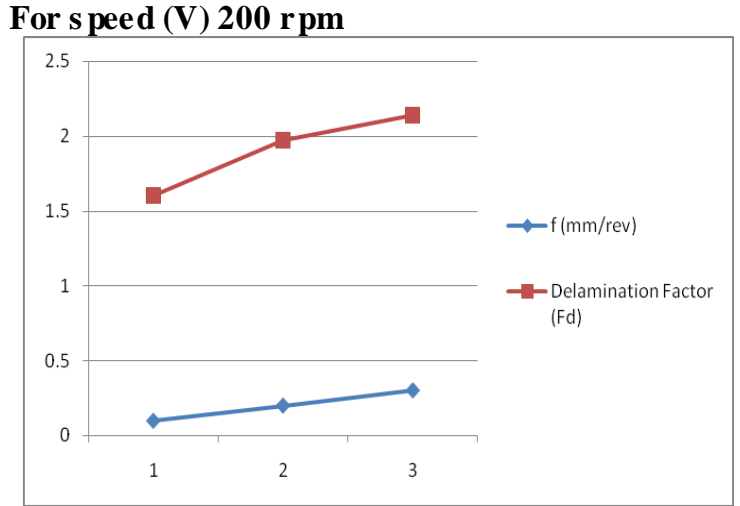

For speed (V) 300 rpm

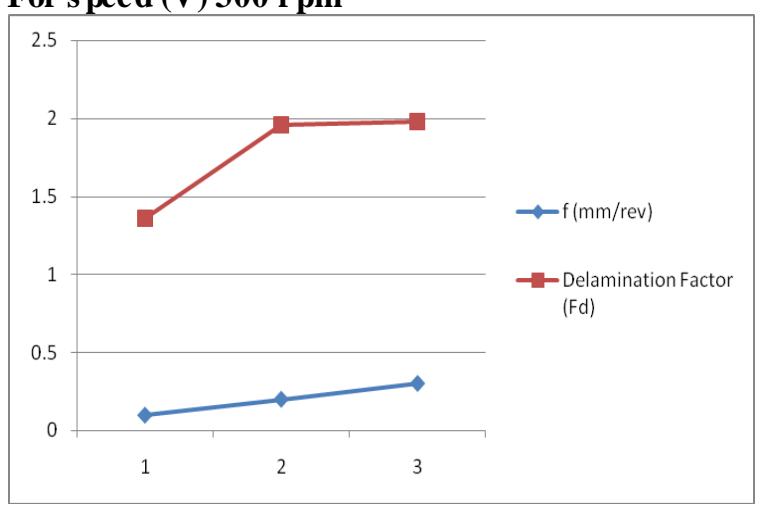

\subsection{Tensile Properties}

The specimen size is $290 \times 24 \times 5 \mathrm{~mm}$. The different composite specimen samples are tested in the universal testing machine (UTM) and the samples are left to break till the ultimate tensile strength occurs. The Result indicates the Ultimate tensile load of the Composite specimen is $34 \mathrm{KN}$ and the Tensile Strength of the Composite is 272.43 $\mathrm{N} / \mathrm{mm}^{2}$.

\subsection{Flexural Properties}

The specimen of fle xu ral test size is $185 \times 26 \times 4.8 \mathrm{~mm}$. The result indicated that the maximu $m$ applied load up to around $2000 \mathrm{~N}$.

\subsection{Hardness Properties}

The Rockwell harness test carried out for the Composite material and obtained the result as applied $100 \mathrm{~kg}$ for $1 / 16$ inch penetrator the B scale reading is $46 \mathrm{HRB}$.

\section{Drilling Behavior}

Based on the two trial average the delamination factor are recorded and the values of delamination factors of the composite drilled

\section{CONCLUSION}

Thus the Glass Fiber Mat composite sample was fabricated and tested. The composite are subjected to mechanical testing such as Tensile,
Flexural and Hardness Test along with drilling of different Speed and Feed rate. Based on the results, the following conclusions are drawn.

$>$ The Results indicated that the Composite have the Tensile Strength of $272.43 \mathrm{~N} / \mathrm{mm}^{2}$ and an ultimate tensile load of $34 \mathrm{KN}$.

$>$ Testing Results shows the flexural strength of $16.02 \mathrm{~N} / \mathrm{mm}^{2}$.

$>$ In Rockwell hardness test the strength was obtained as 45 to $46 \mathrm{HRB}$.

$>$ The feed rate and cutting speed are seen to contribute the most to the delamination effect.

$>$ Generally, the use of high cutting speed and low feed favor minimum delamination on drilling.

\section{REFERENCES}

[1]. Amit Kumar Tanwer, Mechanical Properties Testing of Uni-directional and Bi-directional Glass Fibre Reinforced Epoxy Based Composites. International Journal of Research in Advent Technology, Vol.2, No.11, November 2014, E-ISSN: 2321-9637

[2]. D. Pitchaiah ${ }^{1}$, K. Lalithababu ${ }^{2}$, Ch. Ramesh $\mathrm{Babu}^{3}$, Experimental Study of the Fatigue Strength of Glass fiber epoxy and Chapstan E-Glass epoxy laminates, International Journal of Modern Engineering Research (IJMER) - Vol. 3, Is sue. 5, Sep - Oct. 2013 pp-2702-2712 ISSN: 2249-6645

[3]. Dilli Babu ${ }^{1} *$, K. Sivaji Babu ${ }^{2}$, B. Uma Maheswar Gowd ${ }^{3}$, Drilling Uni-Directional Fiber-Reinforced Plastics Manufactured by Hand Lay-Up: Influence of Fibers, American Journal of Materials Science and Technology, (2012) 1: 1-10, doi:10.7726/ajmst.2012.1001

[4]. K.A lagarraja ${ }^{1}$,A.Dhamodharan ${ }^{2}$ ,K.Gopinathan ${ }^{3}$,R.Mathan $\quad \mathrm{Raj}^{4} \quad$,K.Ram Kumar $^{5}$, Fabrication and Testing of Fibre Reinforced Polymer Composites Material, IOSR Journal of Mechanical and Civil Engineering (IOSR-JMCE) $e$ - ISSN: 22781684, p-ISSN : 2320-334X PP 27-34

[5]. M.Sakthivel, A Review on thrust force and torque in drilling of glass fiber reinforced polymer composite, International Journal of ChemTech Research, CODEN (USA): IJCRGG ISSN: 0974-4290 Vol.7, No.6, pp 2786-2793, 2014-2015

[6]. B.Ramesh,A.Elayaperu maL,S.Satishkumar, Effect of the standard and special geometry design of a drill body on Quality characteristics and multiple performance Optimization in Drilling of Thick Laminated Composites, Elsevier, www. ScienceDirect.com, Procedia Engineering 97 ( 2014 ) 390 - 401 
[7]. Irina M.M.W, A.I. Azmi, Tan C.L., Lee C.C.and A.N.M Khalil, Evaluation of Mechanical Properties of Hybrid Fiber Reinforced Polymer Composites and Their Architecture, 2nd International Materials, Industrial, and Manufacturing Engineering Conference, MIMEC2015,4-6 February 2015, Bali Indonesia

[8]. M.A.J.Bosco, K.Palanikumar, B.Durga Prasad, A. Velayudham, Influence of machining parameters on delamination in drilling of GFRP-armour steel sandwich composites, M.A.J.Bosco et. al / Procedia Engineering 51 ( 2013 ) $758-763$

[9]. .V Arun, D.Sujay Kumar, M.C.Murugesh, Drilling of $\mathrm{TiO}_{2}$ and $\mathrm{ZnS}$ Filled GFRP Composite, Journal of Minerals and Materials Characterization and Engineering, 2012, 11, 785-789

[10]. B.Ramesh, A.Elayaperumal, S.Sathishkumar, Surface Roughness Analysis in Drilling of GFRP Composite by Tungsten Carbide Tool,ISSN: 2231-5950, Vol-3, Issue-1,2013

[11]. G.Baskaran, S.Gowri, R.Krishnamurthy, Study on vital static properties of Fine Blanking of GFRP Composites with that of Conventional Drilling, Int $\mathrm{J} \mathrm{Adv}$ Manuf Technol (2010) 50:659-666

[12]. B.V.Kavad, A Review Paper on Effects of Drilling on Glass Fiber Reinforced Plastic, B.V. Kavad et al. / Procedia Technology 14 ( 2014 ) 457 - 464

[13]. Sang-Young Kim, Mechanical properties and production quality of hand-layup and vacuum infusion processed hybrid composite materials for GFRP marine structures, Int. J. Nav. Archit. Ocean Eng. (2014) 6:723 736

[14]. D. Abdul budan, Influence of Fibre Volume Reinforcement In drilling GFRP Laminates, Journal of Engineering Science and Technology, Vol. 6, No. 6 (2011) 733 - 744, School of Engineering, Taylor's University

[15]. Rout A. K., and Satapathy A., Study on Mechanical and Tribo-Performance of RiceHusk Filled Glass-Epoxy Hybrid Composites, Materials \& Design, 41 (2012), pp.131-141.

[16]. Syed Altaf Hussain, Machinability of glass fiber reinforced plastic (GFRP) composite materials, International Journal of Engineering, Science and Technology Vol. 3, No. 4, 2011, pp. 103-118

[17]. G. Baskaran \& S. Go wri \& R. Krishnamurthy, Study on vital static properties of fine blanking of GFRP Composites with that of conventional drilling, Int $\mathrm{J}$ Adv Manuf Technol (2010) 50:659-666 DOI $10.1007 / \mathrm{s} 00170-010-252-6$
[18]. Y.D Dwivedi, Sweta Dwivedi, A. Jyothsna, A. Puneeth Kumar, Comparative Study on Aerospace Conventional Engineering Material and Glass Fiber Reinforced Poly mer - An Experimental Approach, International Journal of Research in Aeronautical and Mechanical Engineering, Vol.2 Is sue.1,January 2014. Pgs: 72-76

[19]. Tom sunny, Experimental Studies on Effect of Process Parameters on Delamination in Drilling GFRP Composites using Taguchi Method, Tom sunny et al. / Procedia Materials Science $6 \quad$ ( 2014 ) 1131 1142

[20]. Vikas Sonkar, Multi-Objective Optimization in Drilling of GFRP Composites A Degree of Similarity Approach, Vikas Sonkar et al. / Procedia Materials Science 6 ( 2014 ) 538 543

[21]. Prasanna Kumar Ilankeeran, Axial Tensile Testing of Single Fibres, Modern Mechanical Engineering, 2012, 2, 151-156 